\title{
Improvement in BMI z-score following adenotonsillectomy in adolescents aged 12-18 years: a retrospective cohort study
}

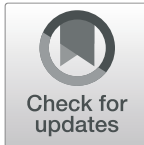

Keren Nathan ${ }^{1 *}$, Galit Livnat ${ }^{2}$, Liat Feraru ${ }^{1}$ and Giora Pillar ${ }^{1,3}$

\begin{abstract}
Background: Characteristics of obstructive sleep apnea (OSA) changes with age. Infants, toddlers and prepubertal children with OSA are usually underweight and may suffer from failure to thrive (FTT). Adenotonsillectomy (T\&A) is the first line of treatment for OSA in childhood. In adults OSA is commonly associated with obesity and the metabolic syndrome. The change in body mass index (BMI) in adolescents with OSA following T\&A was only sporadically studied. Thus, we peruse to examine the BMI z-score change following T\&A in adolescents.
\end{abstract}

Methods: Clalit Health Services is the largest health care organization in Israel with the largest patient registry (more than 50\% of the population). Two hundred and forty two adolescents aged 12-18 who underwent T\&A between 2006 and 2015 were identified in the Clalit registry and their characteristics including height and weight were retrieved. The BMI z-score of these adolescents at baseline (up to 3 months prior to T\&A) and during the consecutive 3 years after T\&A were analyzed and compared.

Results: Changes in BMI Z-score were observed to all directions following T\&A with overall small increase, not statistically significant $(P=0.26)$ from a median of 0.79 prior to T\&A to a median of 0.835 after it. There was a minimal trend toward BMI $z$-score reduction in overweight children $(n=74)$ from 1.508 to 1.48 following T\&A ( $p=\mathrm{NS})$, and in obese children $(n=33)$ from 2.288 to $2.000(P=0.06,2$ tailed). Interestingly thin individuals $(n=6)$ increased their BMl z-score following T\&A from -2.4 to $-0.59(p=0.046)$.

Conclusions: Adolescents show variable changes in their BMI Z-score following T\&A. In this aspect their BMI $z$-score change is closer to the change seen in adults treated for OSA and not that of young children. The changes observed show a trend toward normalization of the BMI z-score such that overweight children tend to decrease their BMI z-score while thin individuals tend to increase it.

Keywords: Obstructive sleep apnea (OSA), Adolescent, BMI z-score, Weight

\footnotetext{
* Correspondence: Keren.nathan@gmail.com

'Department of Pediatrics, Carmel Hospital and Technion Faculty of Medicine, Haifa, Israel

Full list of author information is available at the end of the article
}

(c) The Author(s). 2021 Open Access This article is licensed under a Creative Commons Attribution 4.0 International License, which permits use, sharing, adaptation, distribution and reproduction in any medium or format, as long as you give appropriate credit to the original author(s) and the source, provide a link to the Creative Commons licence, and indicate if changes were made. The images or other third party material in this article are included in the article's Creative Commons licence, unless indicated otherwise in a credit line to the material. If material is not included in the article's Creative Commons licence and your intended use is not permitted by statutory regulation or exceeds the permitted use, you will need to obtain permission directly from the copyright holder. To view a copy of this licence, visit http://creativecommons.org/licenses/by/4.0/ The Creative Commons Public Domain Dedication waiver (http://creativecommons.org/publicdomain/zero/1.0/) applies to the data made available in this article, unless otherwise stated in a credit line to the data. 


\section{Background}

Obstructive sleep apnea (OSA) is a common childhood disorder with a prevalence of $1-6 \%$ in the pediatric population $[1,2]$ Clinically the syndrome is characterized by a disordered sleep with snoring and respiratory disturbances due to upper airway obstruction during sleep. For infants and toddlers untreated OSAS can lead to retardation of growth with a failure to thrive which is present in up to $56 \%$ of the children who are diagnosed with OSA [3, 4]. Risk factors for childhood OSA may be to some extent inheritance/genetics $[5,6]$ or obesity $[7$, 8]. Clearly adenotonsillar hypertrophy is the most common cause for OSA in children, and adenotonsillectomy (T\&A) is considered the first line treatment. This is based both on the American Academy of Pediatrics (AAP) and the American Academy of OtolaryngologyHead and Neck Surgery (AAO-HNS) [9]. An association was found between OSA and cardiovascular impairment [10-12] as well as problems with learning and behavior in school aged children [13-15].

During infancy and early childhood, OSA frequently results in failure to thrive (FTT), in up to $50 \%$ of cases. Infants and toddlers under 4-6 years old with FTT seem to benefit from growth acceleration after conducting T\&A with increase in BMI Z-score in these ages [16, 17]. During school years, weight gain was reported in children with OSA treated with T\&A compared to children with OSA who were not treated at a 7-24 months follow up. The increase in BMI Z score was particular in children who were FTT, normal weight and overweight $[18,19]$. In a twin study at the age of 3-12 years, T\&A was associated with an increase of growth and IGF-1 levels compared to their twin none OSA sibling. An early surgical intervention made a significant growth recovery compared to the twin which had a lower BMI Zscore prior to surgery and had a greater increase in BMI Z-score following the surgery, compared with older children who had a greater BMI to begin with but the increase after T\&A was minor [20, 21].

Obesity is a risk for residual and persistent OSA after T\&A. Children with residual OSA showed greater weight gain after T\&A compared to children without residual OSA [22-24]. For Adults tonsillectomy is not usually considered an isolated option to treat OSA as recommended by the American academy of sleep medicine [25]. However BMI is one of the outcome predictors to success for T\&A in treating OSA similarly as with obese adolescents and children [23, 26]. BMI change in adults following treatment for OSA (for example with CPAP or oral appliance) is inconsistent, and studies had reported changes in all directions [27, 28]. Of note, recurrence of OSA was reported in adults after bariatric surgery even without concomitant weight increase [29]. T\&A is the first line of treatment for childhood OSA but for children with mild to moderate OSA it is important to consider pharmacological options. Anti inflammatory treatment with intranasal corticosteroid (ICS) or montelukast or a combination have shown a beneficial effect ( $80 \%$ of participants) especially in the young and nonobese children [30]. A Cochrane review on the other hand suggested insufficient evidence for efficacy for intranasal ICS treatment and only a short term beneficial effect of montelukast [31].

Regardless of the treatment modality used, weight change following treatment was more intensively studied in adults and young children then in adolescents. The current study focusses on adenotonsillectomy (T\&A). While in infants and young children T\&A is associated with increase in BMI Z score and in adults, changes had been reported in all directions, there are very sparse data in this regard in adolescents. Therefore, the aim of the current study was to examine the BMI $z$-score change following $\mathrm{T} \& \mathrm{~A}$ in adolescents, utilizing a large and well updated registry. We hypothesized that unlike young children, adolescents BMI change following T\&A will be variable, similarly as seen in adults.

\section{Methods}

Clalit Health Services is the largest health care clinics organization in Israel, insuring over 4.5 million people (more than $50 \%$ of the population). It maintains a very strict registry, which includes: patients records, physician visits and surgeries, several studies were published based on queries of this registry [32-34]. Each pediatrician (or ENT) visit is recorded in this registry, and pediatricians are encouraged to measure weight and height at least annually and record it in the registry. Of this registry, a retrospective investigation was preformed to include adolescents aged $12-18$ years who underwent T\&A in between 2006 and 2015. BMI z-score change from up to 3 months prior to T\&A was compared to serially BMI measures every year in the 5 years following surgery (up to 2019). The years 2006-2015 were chosen to reflect a 10 years data period, allowing 3-4years of follow up. The registry inquiry resulted in 242 adolescents who underwent T\&A and had a BMI measurement (i.e. both height and weight) in the period of 3 months prior to the operation and at least one measurement in the 3 years following the surgery.

For each recognized case, the following data were pulled out from the registry: age, weight, height, gender, race, $\mathrm{z}$ score calculated from height and weight (at each timepoint). BMI z-score was categorized (based on the WHO) into 5 categories: Severe thinness (defined as $\mathrm{SD}<-3$ ), thinness-underweight (SD -2 to -3 ), normal $(\mathrm{SD}-2$ to +1$)$, overweight $(\mathrm{SD}+1$ to +2$)$, obesity $(\mathrm{SD}>$ $+2)$. 
statistical analysis was performed by using IBM statistics (SPSS) vs 24. The continuous variables were presented by mean, and standard deviation or Median \& IQR, as appropriate. The categorical variables were presented in percentages. Differences in Z score between baseline and each time point, were assessed using paired t-test or Wilcoxon sign rank test, as appropriate (2 tails). Correlation between $\mathrm{z}$ scores and demographical and clinical characteristics were analyzed using Chi square test for the categorical variables and or Spearman correlation for the continuous variables. $P<0.05$ was considered statistically significant.

The study was approved by the Israeli Clalit Helsinki community committee registered number 0222-16com2. Participants did not have to sign a consent form. A waiver was obtained from the IRB committee. The data extracted from the registry did not include personal information such as patient's names or identity numbers, each patient was assigned a serial number.

\section{Results}

Demographic data of the participants are listed in Table 1. Race and gender did not affect BMI Z-score outcome and therefore data are shown together for the whole cohort. Approximately $50 \%$ of the subjects in this cohort were in the normal range for BMI, z-score while $40 \%$ were overweight and obese. For the whole group $(n=242)$, there was a small trend of increase in BMI Z-score with a median of 0.79 prior to and 0.835 following T\&A $(P=0.26)$. Categorization of the data based on age at the time of surgery is shown in Table 2 and Fig. 1. Data were divided into 3 age categories: $12-14$ (132 subjects), $14-16$ (60

Table 1 General population characteristics

\begin{tabular}{ll}
\hline Variables & $\mathbf{N = 2 4 2 ( \% )}$ \\
\hline Sex & $143(59.1)$ \\
Female & \\
Ethnic group & $91(37.6)$ \\
Arabs & $6(2.5)$ \\
Jewish religious & $145(59.9)$ \\
General & \\
Age category & $132(54.3)$ \\
12-14years & $60(24.7)$ \\
14-16years & $50(20.6)$ \\
16-18years & \\
Z score category: & $127(52.5)$ \\
Normal & $74(30.6)$ \\
Overweight & $33(13.6)$ \\
Obesity & $6(2.5)$ \\
Thinness & $2(0.8)$ \\
Severe Thinness &
\end{tabular}

subjects), and 16-18 (50 subjects) years. BMI z-score had changed to all directions. There was a trend to increase in BMI z-score in the younger age group from a median of 0.9 to $0.94(P=0.169)$, while in the other two age subgroups there were no changes in the median scores. BMI z-score category (defined by the WHO) changed in $25 \%$ of the children following the surgery, but the changes were in an inconsistent way and in all directions (Table 3). Of 242 participants 179 remained in their BMI z-score category (105 in normal BMI category, 53 overweight, and 21 obese). In normal weight category, 13 adolescents changed to higher BMI category while 9 changed to lower BMI category. There were even a few adolescents who had a change in two BMI categories with 4 obese subjects lowering their weight to normal range.

Table 4 details the BMI z-score change specifically for each BMI category. There were changes to all directions, resulting in very high standard deviations for the groups. About $30 \%$ of the children had changed their BMI category following the surgery, such that it tended toward the average (normalized). Overweight children $(n=74)$ tended to reduce their BMI z-score from 1.508 to 1.48 following T\&A ( $\mathrm{p}=$ none significant), and in obese children $(n=33)$ BMI $z$-score decreased from 2.288 to 2.000 accordingly ( $P=0.06,2$ tailed). On the other hand, lean individuals $(n=6)$ increased their BMI z-score following T\&A from -2.4 to $-0.59(p=0.046)$, and in very thin individuals BMI Z-score increased dramatically from 3.7 to -1.1 ( $p=0.18, n=2$ - underpowered).

\section{Discussion}

In this retrospective big data-based study performed on a large group of adolescents aged 12-18 years who underwent T\&A for OSA. We observed that BMI zscore may change in any direction, with a tendency toward normalization of BMI $\mathrm{z}$-score. Underweight and severe lean adolescents tended to increase their BMI zscore 3 years following the surgery, while overweight and obese individuals tended to reduce it. Age, gender and race had no effect on outcome and could not predict BMI z-score change following T\&A. In the underweight category BMI Z-score increased significantly while in the severe thinness group there were only 2 individuals, but both showed a substantial BMI z-score increase following the surgery. Thus, it can be said that T\&A worked in the direction of "normalization" of z-score.

It has been well documented that there is a strong link between OSA and the metabolic syndrome in adults which is multifactorial and is a consequence of visceral obesity and insulin resistance. There is a bidirectional feedforward association between them, with weight modification always being part of the treatment [35]. While infants with OSA are frequently underweight (usually suffer from failure to thrive), and adults with 
Table 2 BMI Z-score data prior to and 3 years following T\&A at 3 age group categories

\begin{tabular}{|c|c|c|c|}
\hline Age Categories & Z-score BMI Before & Median $\mathrm{Z}$ score at 3 years & $P$-value \\
\hline $12-14$ years & $N=132$ & $N=132$ & 0.169 \\
\hline Mean & .7590 & .7820 & \\
\hline Median & .9000 & .9425 & \\
\hline Std. Deviation & 1.17618 & 1.23738 & \\
\hline \multicolumn{4}{|l|}{ Percentiles } \\
\hline 25 & -0.0575 & 0.1425 & \\
\hline 50 & 0.9000 & 0.9425 & \\
\hline 75 & 1.7800 & 1.8563 & \\
\hline $14-16$ years & $N=60$ & $N=60$ & 0.306 \\
\hline Mean & 0.3988 & 0.5395 & \\
\hline Median & 0.6750 & 0.6750 & \\
\hline Std. Deviation & 1.39603 & 1.16127 & \\
\hline \multicolumn{4}{|l|}{ Percentiles } \\
\hline 25 & -0.5525 & -0.2813 & \\
\hline 50 & 0.6750 & 0.6750 & \\
\hline 75 & 1.3650 & 1.3200 & \\
\hline $16-18$ years & $N=50$ & $N=50$ & 0.173 \\
\hline Mean & 0.4016 & 0.3999 & \\
\hline Median & 0.4400 & 0.4450 & \\
\hline Std. Deviation & 1.52683 & 1.41840 & \\
\hline \multicolumn{4}{|l|}{ Percentiles } \\
\hline 25 & -0.8150 & -0.6263 & \\
\hline 50 & 0.4400 & 0.4450 & \\
\hline 75 & 1.8200 & 1.6350 & \\
\hline
\end{tabular}

\section{Median Z score BMI before and after subanalysis} age group

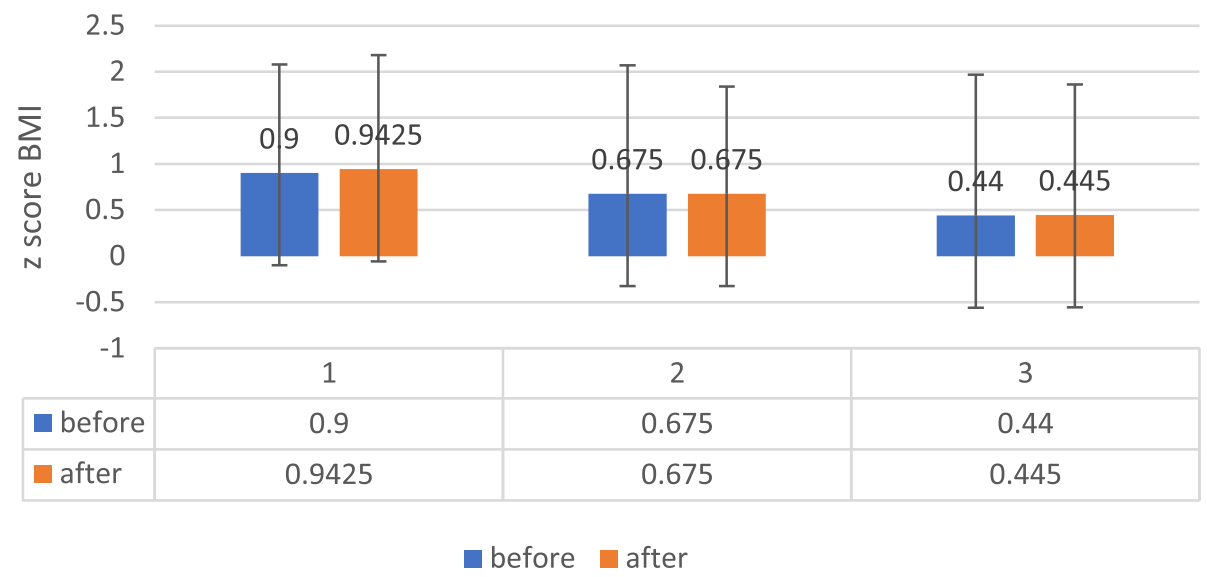

Fig. 1 Median Z score in the 3 age groups 12-14 years (1), 14-16 years (2) and above 16 years (3) 
Table 3 Z-score categories prior to and 3 years following T\&A-crosstabulation

\begin{tabular}{|c|c|c|c|c|c|c|}
\hline & \multicolumn{5}{|c|}{ Median Z-score BMI at 3 years } & \multirow[t]{2}{*}{ Tota } \\
\hline & Normal & Overweight & Obesity & Thinness & Severe Thinness & \\
\hline \multicolumn{7}{|l|}{ Z score BMI before } \\
\hline Normal & 105 & 13 & 0 & 8 & 1 & 127 \\
\hline Overweight & 10 & 53 & 11 & 0 & 0 & 74 \\
\hline Obesity & 4 & 8 & 21 & 0 & 0 & 33 \\
\hline Thinness & 4 & 1 & 0 & 0 & 1 & 6 \\
\hline Severe Thinness & 1 & 0 & 0 & 1 & 0 & 2 \\
\hline Total & 124 & 75 & 32 & 9 & 2 & 242 \\
\hline
\end{tabular}

OSA are frequently overweight, in adolescents data are less clear, although in recent years adolescent OSA was reported to increase due to obesity [36, 37] .

In our study $60 \%$ of the adolescents were not obese or overweigh, which might partially explain why as a group there was a small trend of increase in BMI Z score following T\&A. Interestingly, the two groups of overweight and obese accounting for approximately $40 \%$ of the participants tended to reduce their BMI Z score in the long term follow up after T\&A. This is an encouraging and relatively novel finding for adolescents, indicating that OSA may contribute to obesity and thus OSA treatment may result in weight reduction as we have previously suggested in adults $[38,39]$. In contrast, other studies exploring the association of T\&A and weight reduction demonstrated an increase in BMI following T\&A. Amin et al. demonstrated an increase in BMI after 1 year following T\&A in school age children (7-13 years) especially for those who were obese at baseline. The velocity of the BMI increase after T\&A was an independent risk factor for OSA recurrence [40]. Other studies including a systematic review as well showed similar results, but they all included wide age range from 0 to 18 years old with no stratification according to age subgroups and different outcome for obese and normal weight children $[41,42]$. Potential mechanisms for weight reduction following T\&A may include reduced appetite (which is known to be high in sleepy individuals due to Ghrelin secretion), increase in physical activity (which is a direct result from reduction of sleepiness), and improvement in insulin sensitivity. Other components of the metabolic syndrome, lipid profile and insulin resistance in obese children and adolescents have been shown to improve with the resolution of OSA after T\&A [28, 43, 44]. Our data in this study supports the notion of having two OSA phenotype that change around puberty, from lymphadenoid hypertrophy to an OSA related more to obesity [45]. The unpredicted changes observed to all directions in our study resembles findings from juvenile rat studies and clinical trials, in which the removal of airway obstruction was not able to restore the dysregulated hormonal axes [46] and other lifestyle behaviors (high caloric intake, physical activity) had a strong influence $[47,48]$. Seven weeks following obstruction removal in juvenile rats showed that these animals still had high ghrelin levels and consumed more food, yet exhibited growth retardation due to deregulation of $\mathrm{GH}$ homeostasis [46]. Although the participants in the current study were adolescents (not exactly parallel to juvenile rats), increased ghrelin levels and food consumption, along with dysregulation of $\mathrm{GH}$ release, may explain substantial increase in BMI Z score as was observed in our underweight and severe lean participants, although such potential mechanisms will require a future study.

In a study aimed to examine anatomical parameters in adolescents using MRI, obese adolescents with OSAS had increased adenotonsillar tissue compared with obese and lean control subjects (total of 137 subjects) without OSAS. Lymphoid tissue, rather than other soft tissue components, was the primary structural abnormality in obese adolescents. This finding supports adenotonsillectomy to be considered as treatment for OSAS in these obese adolescents, as opposed to adults in whom T\&A is commonly insufficient, requiring treatment with CPAP or weight reduction [49]. In another study, in obese children and adolescents aged 7-18 years, OSA improved with weight reduction in the same manner as obese adults are responding to weight reduction [50]. Thus, our study indicates that T\&A may improve weight, suggesting that OSA itself contributes to the weight increase process in adolescents.

On the other hand, very lean (underweight and severe underweight) adolescents responded with BMI z-score increase following T\&A. The mechanism for this is unclear. In infants OSA is associated with FTT with suggested mechanisms of reduced calorie intake and increased energy expenditure due to work of breathing. We did not assess food intake or work of breathing in our retrospective study and cannot confirm or rule out these mechanisms in our adolescents. However, it is important to point out that of the 8 cases in these 
Table 4 BMI z-score changes up to 3 years following T\&A based on BMl z-score category prior to surgery

\begin{tabular}{|c|c|c|c|}
\hline $\begin{array}{l}\text { BMI z-score } \\
\text { Categories }\end{array}$ & $\begin{array}{l}\text { Z-score BMI } \\
\text { Before }\end{array}$ & $\begin{array}{l}\text { Median } Z \text { score at } 3 \\
\text { years }\end{array}$ & $P$-value \\
\hline Normal & $N=127$ & $N=127$ & 0.140 \\
\hline Mean & -0.1665 & -0.11 & \\
\hline Median & 0.0500 & 0.14 & \\
\hline Std. Deviation & 0.83631 & 1.024 & \\
\hline \multicolumn{4}{|l|}{ Percentiles } \\
\hline 25 & -0.7600 & -0.6500 & \\
\hline 50 & 0.0500 & 0.1400 & \\
\hline 75 & 0.5100 & 0.6300 & \\
\hline Overweight & $N=74$ & $N=74$ & 0.798 \\
\hline Mean & 1.5082 & 1.48 & \\
\hline Median & 1.5250 & 1.53 & \\
\hline Std. Deviation & 0.30918 & 0.504 & \\
\hline \multicolumn{4}{|l|}{ Percentiles } \\
\hline 25 & 1.5082 & 1.48 & \\
\hline 50 & 1.5250 & 1.53 & \\
\hline 75 & 0.30918 & 0.504 & \\
\hline Obesity & $N=33$ & $N=33$ & 0.064 \\
\hline Mean & 2.2882 & 2.00 & \\
\hline Median & 2.2100 & 2.17 & \\
\hline Std. Deviation & 0.24558 & 0.730 & \\
\hline \multicolumn{4}{|l|}{ Percentiles } \\
\hline 25 & 2.1150 & 1.8650 & \\
\hline 50 & 2.2100 & 2.1700 & \\
\hline 75 & 2.4000 & 2.4250 & \\
\hline Thinness & $N=6$ & $N=6$ & 0.046 \\
\hline Mean & -2.4000 & -0.59 & \\
\hline Median & -2.3350 & -0.64 & \\
\hline Std. Deviation & .31875 & 1.707 & \\
\hline \multicolumn{4}{|l|}{ Percentiles } \\
\hline 25 & -2.5950 & -1.7000 & \\
\hline 50 & -2.3350 & -0.6350 & \\
\hline 75 & -2.1775 & 0.7675 & \\
\hline Severe thinness & $N=2$ & $N=2$ & 0.180 \\
\hline Mean & -3.6900 & -1.11 & \\
\hline Median & -3.6900 & -1.11 & \\
\hline Std. Deviation & 0.35355 & 1.273 & \\
\hline \multicolumn{4}{|l|}{ Percentiles: } \\
\hline 25 & -3.9400 & -2.0100 & \\
\hline 50 & -3.6900 & -1.1100 & \\
\hline 75 & & & \\
\hline
\end{tabular}

categories, 6 gained weight and moved up to normal BMI category, and only 1 individual became overweight the remaining 8th individual reduced weight and changed from thinness to severe thinness category (Table 3). Obviously, our study suffers from being underpowered for underweight adolescents $(n=8)$, yet due to the dramatic weight gain these changes were statistically significant. Further studies are required to better understand this (small) subgroup of underweight adolescents with OSA, and the effect of T\&A on them.

The strengths of our study are the large number of participants, being a real "field" study indicating changes observed in "real life" with no research intervention, and the relatively large follow up period ( 3 years for all, in some up to 5 years). On the other hand, there are several limitations in our study. First, this is a retrospective data base study. However, we believe that the well-kept registry of Clalit together with the large number of participants still makes the results of this study valid and representative. Actually, the fact that this is a "field study" report and not prospective weight-change followup study makes it somewhat more representative of the "real" clinical world. Second, PSG numerical results (i.e. apnea hypopnea index, oxygen saturation, sleep time etc.) were not available from the Clalit registry. We only had the diagnosis code for OSA. Thus, we cannot provide data regarding the effect of T\&A on OSA in our study, or the correlation between change in OSA and change in BMI z-score. We can only make a logical guess that at least in those with substantial weight reduction following T\&A OSA was improved but again we cannot support it by data in our study. However, it is supported by some data from previous studies. Finally, the data represents only the insurers of Clalit, thus cannot be automatically generalized for the whole Israeli population. However, we believe that it is quiet representative and are unaware of any specific weight or OSA related data and preference of other medical insurance. Thus, we believe these results are representative and generalizable.

\section{Conclusion}

Despite the above-mentioned limitations, we believe our study results are valid and representative. Adolescents following T\&A show variable changes in BMI z-score, with a tendency toward normalization of it. In the subgroups of underweight T\&A resulted in BMI z-score increase, while in overweight and obese adolescents, it resulted in a tendency toward BMI z-score reduction. In these regards, the observations resemble the changes seen in adults and not in young children. Further studies are needed in this age group to characterize adolescent's OSAS features and BMI change following T\&A, and the correlation between them. 


\section{Abbreviations}

BMI: Body mass index; CPAP: Continues positive airway pressure; FTT: Failure to thrive; OSAS: Obstructive sleep apnea syndrome; T\&A: Tonsillectomy and adenoidectomy

\section{Acknowledgements \\ Not applicable.}

\section{Authors' contributions}

All authors contributed to the study conception and design. Material preparation, data collection and analysis were performed by KN, GL, LF and GP. The first draft of the manuscript was written by KN. All authors commented on previous versions of the manuscript. All authors read and approved the final manuscript.

\section{Funding}

There is no funding source.

\section{Availability of data and materials}

The data that support the findings of this study are available from Clalit data committee but restrictions apply to the availability of these data, which were used under license for the current study, and so are not publicly available. Data are however available from the authors upon reasonable request and with permission of Clalit data committee.

\section{Declarations}

\section{Ethics approval and consent to participate}

The study was approved by the Israeli Clalit Helsinki community committee registered number 0222-16-com2 Michalne3@clalit.org.il. A consent waiver was received from the Helsinki committee. The data extracted from the registry did not include personal information such as patients names or identity numbers, each patient was assigned a serial number.

\section{Consent for publication}

Not applicable.

\section{Competing interests}

The authors declare that they have no competing interests in this section.

\section{Author details}

'Department of Pediatrics, Carmel Hospital and Technion Faculty of Medicine, Haifa, Israel. ${ }^{2}$ Pediatric Pulmonary Unit \& CF Center, Carmel Medical Center, Haifa, Israel. ${ }^{3}$ Sleep Clinic, Carmel Hospital and Technion Faculty of Medicine, Haifa, Israel.

\section{Received: 13 July 2020 Accepted: 29 March 2021}

Published online: 20 April 2021

\section{References}

1. Baugh RF, Archer SM, Mitchell RB, Rosenfeld RM, Amin R, Burns JJ, et al. Clinical practice guideline: tonsillectomy in children. Otolaryngol Neck Surg. 2011:144(1_suppl):S1-S30. https://doi.org/10.1177/0194599810389949.

2. Roland PS, et al. Clinical practice guideline: Polysomnography for sleepdisordered breathing prior to tonsillectomy in children. Otolaryngol Head Neck Surg. 2011;145:S1-5.

3. Bonuck K, Parikh S, Bassila M. Growth failure and sleep disordered breathing: a review of the literature. [Review] [93 refs]. Int J Pediatr Otorhinolaryngol. 2006;70(5):769-78.

4. Brouillette RT, Fernbach SK, Hunt CE. Obstructive sleep apnea in infants and children. J Pediatr. 1982;100(1):31-40. https://doi.org/10.1016/S0022-3476(82 80231-X.

5. Pillar $G$, Lavie P. Assessment of the role of inheritance in sleep apnea syndrome. Am J Respir Crit Care Med. 1995;151(3_pt_1):688-91. https://doi. org/10.1164/ajrccm/151.3_Pt_1.688

6. Pillar G, Schnall RP, Peled N, Oliven A, Lavie P. Impaired respiratory response to resistive loading during sleep in healthy offspring of patients with obstructive sleep apnea. Am J Respir Crit Care Med. 1997:155(5):1602-8. https://doi.org/10.1164/ajrccm.155.5.9154864.
7. Hering E, Pritsker I, Gonchar L, Pillar G. Obesity in children is associated with increased health care use. Clin Pediatr. 2009. https://doi.org/10.1177/ 0009922809336072

8. Tan HL, Gozal D, Kheirandish-Gozal L. The status of pediatric obstructive sleep apnea in 2015: Progress? YES!! More questions? Definitely YES!! Curr Sleep Med Reports. 2016;2(1):20-30. https://doi.org/10.1007/s40675-0160033-4.

9. Marcus CL, Brooks LJ, Draper KA, Gozal D, Halbower AC, Jones J, et al. Diagnosis and management of childhood obstructive sleep apnea syndrome. Pediatrics. 2012;130(3):e714-55. https://doi.org/10.1542/peds.2 012-1672.

10. Kheirandish-Gozal L, Etzioni T, Bhattacharjee R, Tan HL, Samiei A, Molero Ramirez $\mathrm{H}$, et al. Obstructive sleep apnea in children is associated with severity-dependent deterioration in overnight endothelial function. Sleep Med. 2013;14(6):526-31. https://doi.org/10.1016/j.sleep.2013.02.010.

11. Marcus $\mathrm{CL}$, Greene MG, Carroll JL. Blood pressure in children with obstructive sleep apnea. Am J Respir Crit Care Med. 1998;157(4):1098-103. https://doi.org/10.1164/ajrccm.157.4.9704080.

12. O'Driscoll DM, Horne RSC, Davey MJ, Hope SA, Anderson V, Trinder J, et al. Increased sympathetic activity in children with obstructive sleep apnea: cardiovascular implications. Sleep Med. 2011;12(5):483-8. https://doi.org/10.1 016/j.sleep.2010.09.015

13. Beebe DW, Ris MD, Kramer ME, Long E, Amin R. The association between sleep disordered breathing, academic grades, and cognitive and behavioral functioning among overweight subjects during middle to late childhood. Sleep. 2010;33(11):1447-56. https://doi.org/10.1093/sleep/33.11.1447.

14. Golan N, Shahar E, Ravid S, Pillar G. Sleep disorders and daytime sleepiness in children with attention-deficit/hyperactive disorder. Sleep. 2004;27(2): 261-6. https://doi.org/10.1093/sleep/27.2.261.

15. Ravid S, Afek I, Suraiya S, Shahar E, Pillar G. Sleep disturbances are associated with reduced school achievements in first-grade pupils. Dev Neuropsychol. 2009;34(5):574-87. https://doi.org/10.1080/87565640903133533.

16. Czechowicz JA, Chang KW. Analysis of growth curves in children after adenotonsillectomy. JAMA Otolaryngol Head Neck Surg. 2014;140(6):491-6. https://doi.org/10.1001/jamaoto.2014.411.

17. Smith DF, Vikani AR, Benke JR, Boss EF, Ishman SL. Weight gain after adenotonsillectomy is more common in young children. Otolaryngol Head Neck Surg. 2013;148:488-93.

18. Katz ES, Moore RH, Rosen CL, Mitchell RB, Amin R, Arens R, et al. Growth after Adenotonsillectomy for obstructive sleep apnea: an RCT. Pediatrics. 2014;134(2):282-9. https://doi.org/10.1542/peds.2014-0591.

19. Tahara $\mathrm{S}, \mathrm{Hara} H$, Yamashita $H$. Evaluation of body growth in prepubertal Japanese children with obstructive sleep apnea after adenotonsillectomy over a long postoperative period. Int J Pediatr Otorhinolaryngol. 2015; 79(11):1806-9. https://doi.org/10.1016/j.ijporl.2015.08.005.

20. Zhang XM, Shi J, Meng GZ, Chen HS, Zhang LN, Wang ZY, et al. The effect of obstructive sleep apnea syndrome on growth and development in nonobese children: a parallel study of twins. J Pediatr. 2015;166(3):646-50. https://doi.org/10.1016/j.jpeds.2014.11.060.

21. Levi J, Leoniak S, Schmidt R. Evaluating tonsillectomy as a risk factor for childhood obesity. Arch Otolaryngol Head Neck Surg. 2012;138(10):897-901 https://doi.org/10.1001/2013.jamaoto.252.

22. Alonso-Álvarez ML, Terán-Santos J, Navazo-Egüia Al, Martinez MG, JuradoLuque MJ, Corral-Peñafiel J, et al. Treatment outcomes of obstructive sleep apnoea in obese community-dwelling children: the NANOS study. Eur Respir J. 2015:46(3):717-27. https://doi.org/10.1183/09031936.00013815.

23. Com G, et al. Characteristics and surgical and clinical outcomes of severely obese children with obstructive sleep apnea. J Clin Sleep Med. 2015;11:467-74

24. Andersen IG, Holm JC, Homøe P. Obstructive sleep apnea in obese children and adolescents, treatment methods and outcome of treatment - a systematic review. Int J Pediatr Otorhinolaryngol. 2016;87:190-7. https://doi. org/10.1016/j.jporl.2016.06.017.

25. Aurora, R. N. et al. Practice parameters for the surgical modifications of the upper airway for obstructive sleep apnea in adults. (1996).

26. Tauman R, Gulliver TE, Krishna J, Montgomery-Downs HE, O'Brien LM, Ivanenko $A$, et al. Persistence of obstructive sleep apnea syndrome in children after adenotonsillectomy. J Pediatr. 2006;149(6):803-8. https://doi. org/10.1016/j.jpeds.2006.08.067.

27. Da Chen $L$, et al. Effect of continuous positive airway pressure on adiponectin in patients with obstructive sleep apnea: a meta-analysis. PLoS One. 2015;10:1-11 
28. Tauman R, O'Brien LM, Ivanenko A, Gozal D. Obesity rather than severity of sleep-disordered breathing as the major determinant of insulin resistance and altered lipidemia in snoring children. Pediatrics. 2005;116(1):e66-73. https://doi.org/10.1542/peds.2004-2527.

29. Pillar G, Peled R, Lavie P. Recurrence of sleep apnea without concomitant weight increase 7.5 years after weight reduction surgery. Chest. 1994;106(6): 1702-4. https://doi.org/10.1378/chest.106.6.1702.

30. Kheirandish-Gozal L, Bhattacharjee R, Bandla HPR, Gozal D. Antiinflammatory therapy outcomes for mild OSA in children. Chest. 2014;146(1):88-95. https://doi.org/10.1378/chest.13-2288.

31. Kuhle S, Hoffmann DU, Mitra S, Urschitz MS. Anti-inflammatory medications for obstructive sleep apnoea in children. Cochrane Database Syst Rev. 2020; 2020:1-36.

32. Manolio TA, et al. Global implementation of genomic medicine: we are not alone. Sci Transl Med. 2015;7:1-9.

33. Safadi A, Etzioni T, Fliss D, Pillar G, Shapira C. The effect of the transition to home monitoring for the diagnosis of OSAS on test availability, waiting time, patients' satisfaction, and outcome in a large health provider system. Sleep Disord. 2014;2014:1-6. https://doi.org/10.1155/2014/418246.

34. Tarasiuk A, Greenberg-Dotan S, Brin YS, Simon T, Tal A, Reuveni H. Determinants affecting health-care utilization in obstructive sleep apnea syndrome patients. Chest. 2005;128(3):1310-4. https://doi.org/10.1378/ chest.128.3.1310.

35. Gaines J, Vgontzas AN, Fernandez-Mendoza J, Bixler EO. Obstructive sleep apnea and the metabolic syndrome: the road to clinically-meaningful phenotyping, improved prognosis, and personalized treatment. Sleep Med Rev. 2018:1-9. https://doi.org/10.1016/j.smrv.2018.08.009.

36. Andersen IG, Holm JC, Homøe P. Obstructive sleep apnea in children and adolescents with and without obesity. Eur Arch Oto Rhino Laryngol. 2019; 276(3):871-8. https://doi.org/10.1007/s00405-019-05290-2.

37. Gohil A, Hannon TS. Poor sleep and obesity: concurrent epidemics in adolescent youth. Front Endocrinol. 2018;9(1-8). https://doi.org/10.3389/ fendo.2018.00364

38. Fisher D, Pillar G, Malhotra A, Peled N, Lavie P. Long-term follow-up of untreated patients with sleep apnoea syndrome. Respir Med. 2002;96(5): 337-43. https://doi.org/10.1053/rmed.2001.1277.

39. Pillar G, Shehadeh N. Abdominal fat and sleep apnea. Diabetes Care. 2008; 31(Supplement 2):S303-9. https://doi.org/10.2337/dc08-s272.

40. Amin R, Anthony L, Somers V, Fenchel M, McConnell K, Jefferies J, et al. Growth velocity predicts recurrence of sleep-disordered breathing 1 year after adenotonsillectomy. Am J Respir Crit Care Med. 2008;177(6):654-9. https://doi.org/10.1164/rccm.200710-16100C.

41. Lewis TL, Johnson RF, Choi J, Mitchell RB. Weight gain after adenotonsillectomy: a case control study. Otolaryngol Head Neck Surg. 2015:152:734-9.

42. Jeyakumar A, Fettman N, Armbrecht ES, Mitchell R. A systematic review of adenotonsillectomy as a risk factor for childhood obesity. Otolaryngol Head Neck Surg. 2011;144(2):154-8. https://doi.org/10.1177/0194599810392328.

43. Alonso-Alvarez ML, et al. Metabolic biomarkers in community obese children: effect of obstructive sleep apnea and its treatment. Sleep Med. 2017:37:1-9. https://doi.org/10.1016/j.sleep.2017.06.002

44. Verhulst SL, Schrauwen N, Haentjens D, Rooman RP, van Gaal L, de Backer WA, et al. Sleep-disordered breathing and the metabolic syndrome in overweight and obese children and adolescents. J Pediatr. 2007;150(6):60812. https://doi.org/10.1016/j.jpeds.2007.01.051.

45. Koren D, Gozal D, Philby MF, Bhattacharjee R, Kheirandish-Gozal L. Impact of obstructive sleep apnoea on insulin resistance in nonobese and obese children. Eur Respir J. 2016;47(4):1152-61. https://doi.org/10.1183/13993003. 01430-2015.

46. Assadi MH, Shknevsky E, Segev Y, Tarasiuk A. Abnormal growth and feeding behavior persist after removal of upper airway obstruction in juvenile rats. Sci Rep. 2017;7:1-10

47. Tachikawa R, Ikeda K, Minami T, Matsumoto T, Hamada S, Murase K, et al. Changes in energy metabolism after continuous positive airway pressure for obstructive sleep apnea. Am J Respir Crit Care Med. 2016;194(6):729-38. https://doi.org/10.1164/rccm.201511-23140C.

48. Shechter A. Obstructive sleep apnea and energy balance regulation: a systematic review. Sleep Med Rev. 2017;34:59-69. https://doi.org/10.1016/j. smrv.2016.07.001.

49. Schwab RJ, Kim C, Bagchi S, Keenan BT, Comyn FL, Wang S, et al. Understanding the anatomic basis for obstructive sleep apnea syndrome in adolescents. Am J Respir Crit Care Med. 2015;191(11):1295-309. https://doi. org/10.1164/rccm.201501-01690C.

50. Andersen IG, Holm JC, Homøe P. Impact of weight-loss management on children and adolescents with obesity and obstructive sleep apnea. Int J Pediatr Otorhinolaryngol. 2019;123:57-62. https://doi.org/10.1016/j.ijporl.201 9.04.031.

\section{Publisher's Note}

Springer Nature remains neutral with regard to jurisdictional claims in published maps and institutional affiliations.
Ready to submit your research? Choose BMC and benefit from:

- fast, convenient online submission

- thorough peer review by experienced researchers in your field

- rapid publication on acceptance

- support for research data, including large and complex data types

- gold Open Access which fosters wider collaboration and increased citations

- maximum visibility for your research: over $100 \mathrm{M}$ website views per year

At BMC, research is always in progress.

Learn more biomedcentral.com/submissions 